\title{
Notas sobre práticas educativas diferenciadas no MST: os princípios pedagógicos revelados a partir de algumas metodologias empregadas na educação do movimento
}

\author{
Liene Keite de Lira da Mata ${ }^{1}$ \\ ${ }^{1}$ Escola Municipal de Educação Infantil Nivando Mariano dos Santos - EMEF. Rua Francisco da Costa Pimentel, \\ 311, Santa Clara, Marília - SP. Brasil. lienekeite@yahoo.com.br.
}

RESUMO. O presente artigo assinala alguns princípios pedagógicos e práticas educativas diferenciadas no MST conjecturando uma nova concepção de educação para os sujeitos do campo. Com base em pesquisa de mestrado concluída, em alguns questionamentos suscitados na Jornada de Formação de Professores e a práxis como educadora de crianças, foi possível iniciar uma discussão sobre princípios pedagógicos e práticas educativas mais abrangentes no MST. O Movimento valoriza o contexto dos sujeitos que vivem no campo e às crianças e adolescentes, potencializando uma formação de caráter político e humano. Os princípios pedagógicos e as práticas educativas mais abrangentes são abordados como um diferencial para uma aprendizagem com sentido para a vida. Igualmente, desponta a importância do ensino sistematizado e o desafio de diferenciar as práticas educativas respeitando as diversidades sociais e culturais para que os que mais precisam.

Palavras-chave: Educação, MST, Princípios Pedagógicos, Práticas Educativas Diferenciadas. 


\title{
Notes on differentiated educational practices in MST: The pedagogical principles revealed from some methodologies used in movement education
}

\begin{abstract}
This article points out some pedagogical principles and differentiated educational practices in MST speculating a new conception of education for the subject field. Based on completed master's research on some questions raised in the Teacher Training Day, and praxis as children educator, it was to start a discussion about pedagogical principles and most comprehensive educational practices in MST. The Movement values the context of the subjects living in the countryside and children and adolescents enhance one political and human character formation. The pedagogical principles and the most comprehensive educational practices are addressed as a differential to learning meaningful for life. It also stands out the importance of systematic teaching and the challenge of differentiating educational practices respecting the social and cultural diversity for those most in need.
\end{abstract}

Keywords: Education, MST, Pedagogical Principles, Differentiated Educational Practices. 


\section{Notas sobre las prácticas educativas diferenciadas en MST: los principios pedagógicos revelados de algunas metodologías utilizadas en la educación del movimiento}

RESUMEN. Este artículo señala algunos principios pedagógicos y prácticas educativas diferenciadas en MST especulando una nueva concepción de la educación para el campo. En base a la investigación realizada de maestría sobre algunas cuestiones planteadas en el Día de formación del profesorado y la praxis como los niños educador, era comenzar una discusión acerca de los principios pedagógicos y prácticas educativas más completas de MST. El Movimiento valora el contexto de los sujetos que viven en el campo y los niños y adolescentes aumenta la formación de un carácter político y humano. Los principios pedagógicos y las prácticas educativas más completas se tratan como un diferencial a un aprendizaje significativo para la vida. También se destaca la importancia de la enseñanza sistemática y el desafío de la diferenciación de las prácticas educativas, respetando la diversidad social y cultural para los más necesitados, aprender y aprender bien.

Palabras-clave: Educación, MST, Principios Pedagógicos, Las Prácticas Educativas Diferenciadas. 


\section{Introdução}

Este estudo, de natureza teórica, coloca em questão práticas pedagógicas diferenciadas para acolher a realidade dos educandos em seu contexto, como a educação do campo em sua conjunturasimilarmente a respeitar os sujeitos enquanto possuidores de habilidades e características próprias. Aquilata a relação pedagógica sensível ao contexto social e cultural do educando, haja vista a diferenciação em relação ao acesso e condições sociais/culturais. Por consequência, educandos sem condições dignas mínimas, geralmente são os que não têm conseguido aprender e extrair sentido nas práticas escolares. Logo, existe a dificuldade para que todos aprendam, e/ou aprendam bem, e que essa aprendizagem tenha significado para a vida. Assim, o texto aponta princípios pedagógicos revelados a partir de algumas metodologias do movimento empregadas com potencial de aprendizagem para a vida, como a criação de meios de comunicação próprios, e exemplifica ações de mobilização de crianças e adolescentes retratando práticas educativas diferenciadas com caráter de formação humana e política.

István Mészáros (2008) citando José Martí sobre o lugar da escola, ou da formidável prisão por suas várias restrições, idealiza a escola como lugar de emancipação e de realização genuína. "...os princípios orientadores da educação formal devem ser desatados do seu tegumento da lógica do capital, de imposição de conformidade, em vez disso mover-se em direção a um intercâmbio ativo e efetivo e práticas educacionais mais abrangentes." (Mészáros, 2008, p. 58).

Diante de contextos díspares de acesso e condições culturais/sociais, como diferenciar as práticas para que os que mais precisam igualmente aprendam? Princípios e objetivos educativos com significado e consistência originaria a diferenciação nas práticas educativas?

O projeto sociopolítico do MST tem se destacado enquanto proposta de educação no campo. Por meio das ações de luta, realiza uma prática educativa diferenciada mais abrangente, lutando por terra e condições dignas de vida, ao mesmo tempo, luta também por uma educação pública de qualidade para os Sem Terrinha e os Sem Terra, pois insere a educação como princípio para formação humana indispensável.

Segundo o MST, uma das lições que se pode tirar de sua história até aqui é de que lutar somente pela terra não basta. A luta pela reforma agrária deve ser bem mais ampla, implicando a conquista de todos os direitos sociais que compõem o que se poderia chamar de cidadania plena. Nessa perspectiva, a educação é um dos direitos, é um dos direitos, pelo qual também é preciso mobilização, 
organização e luta. É sempre compreendida como processo que deve envolver a participação das crianças, das mulheres, da juventude, dos idosos, construindo novas relações e consciências, incluindo a participação nas marchas, assembleias, cursos, caminhadas, trabalhos voluntários, gestos de solidariedade, ocupações, mobilizações, visando a que se aprenda e ensine, além do alfabeto, o ato de ler e escrever a realidade da vida. (Neto, 2009, p. 11).

Com efeito, para o MST, é impreterível a 'educação' em seu projeto sociopolítico - mas qual educação pensada? Conforme exposto, evidencia-se uma visão integral do conceito educaçãoproposta nos princípios pedagógicos e nas ações educativas do MST, uma vez que vão além dos espaços escolares, propondo uma alternativa omnilateral de formação. Mesmo sendo exemplo em seu projeto, o MST enfrenta conflitos dentro do próprio movimento, ainda mais os grandes obstáculos impostos pela configuração de sociedade capitalista que está inserido. Enfim, o texto pretende assinalar alguns aspectos teóricos/práticos que se conformam em uma metodologia diferenciada.

\section{Princípios pedagógicos}

O direito pela educação é um dos objetivos de mobilização reivindicados pelo Movimento “... o direito de todos e todas à educação, em suas diversas formas, com especial ênfase para escolarização." (Caderno de Educação no 8, 1996). Sendo assim, uma das lutas do MST é por uma educação de qualidade para todos; portanto, criaram o Setor responsável pela Educação, e elaboraram documentos com princípios norteadores. No Caderno já citado, o MST define os princípios filosóficos e pedagógicos dos quais alguns elucidaremos neste texto para visualizarmos um pouco da sua concepção de educação.

O Movimento defende uma aprendizagem para a vida quando elenca o princípio da relação entre prática e teoria. Esta relação se torna importante para que ocorra uma ligação do ensino formal com as demais questões da vida, pois não se esperam dos educandos posturas passivas, mas que exercitem práticas sociais no ambiente escolar. A realidade como base da produção do conhecimento: pretende que os educandos produzam conhecimento sobre a realidade, mas não se refere apenas uma realidade próxima, mas “... a realidade é o mundo! É tudo aquilo que existe e merece ser conhecido, apreciado, transformado e que pode estar a milhares e milhares de quilômetros do assentamento." (Caderno $\left.n^{\circ} 8,1996\right)$. A realidade é ampla mas tem que se conhecer a realidade próxima. É um método pedagógico que parte da realidade próxima para chegar a 
ser ampla, fazendo uma análise entre as duas, intervindo no processo de conhecimento.

Por isso, este método se vale de temas geradores que partem da realidade dos educandos à luz teórica de Paulo Freire, que foi mais do que um educador, mas um pensador humanista preocupado com a formação e libertação da consciência dos oprimidos da classe dominante. Para Freire (1982) a educação libertadora é uma educação problematizadora. Deste modo, requer diálogo crítico, questões provocadoras de novas respostas para tomada de consciência existencial e do mundo. Para tanto, foi sugerido uma investigação a partir do que chamou de "temas geradores" ou "universo temático".

A priori as palavras geradoras surgem do universo dos educandos criando novas palavras (alfabetização). Nesse processo mais do que simplesmente decodificar-codificar palavras, importa à metodologia, dar aos educandos possibilidade de "lerem o mundo", pensando-o, criticando-o, decifrando-o sempre.

Um mínimo de palavras, com a máxima polivalência fonêmica, é o ponto de partida para a conquista do universo vocabular. Essas palavras, oriundas do próprio universo vocabular do alfabetizando, transfiguradas pela crítica, a ele retornam em ação transformadora do mundo. Assim, ao objetivar uma palavra geradora - íntegra, primeiro, é depois decomposta em seus elementos silábicos - o alfabetizando já está motivado para não só buscar o mecanismo de sua recomposição e da composição de novas palavras, mas também para escrever seu pensamento. (Fiori apud Freire, 1982, p. 5-6).

Os temas geradores trabalham a realidade de vida do educando até a compreensão da realidade mais ampla, refletindo nas partes e no todo, ou vice e versa, num processo de reflexão, descodificação da sua visão de mundo, de tal forma que a prática envolve questões em que os homens se acham "coisificados".

\begin{abstract}
Em todas as etapas da descodificação, estarão os homens exteriorizando sua visão de mundo, sua forma de pensá-lo, sua percepção fatalista das "situações-limites", sua percepção estática ou dinâmica da realidade. E, nesta forma expressada de pensar o mundo fatalistamente, de pensá-lo dinâmica ou estaticamente, na maneira como realizam seu enfrentamento com o mundo, se encontram envolvidos seus "temas geradores". (Freire, 1982, p. 115).
\end{abstract}

O tema gerador se faz na relação do homem e o mundo. Dessa maneira, para Freire, o tema não pode ser encontrado isolado da realidade de que fazem parte, por tanto, pesquisar o tema gerador é 
investigar o pensar referido à realidade, é investigar seu atuar sobre a realidade, realizando a práxis.

Em relação ao currículo é necessário organizar um que exija respostas práticas dos estudantes. Assim, o desafio metodológico é de como articular o maior número de saberes diante de situações da realidade. Compreendem que há mais de uma maneira de aprender e de ensinar, num processo de estudo e reflexão sobre metodologias, por isso, defendem um ensino que parta da prática, também a combinação metodológica entre processos de ensino e de capacitação. Põem uma diferença entre os dois processos buscando integra-los. Os processos de ensino com os de capacitação nas escolas ou cursos terão que estabelecer não apenas os conteúdos a serem trabalhados, mas também habilidades ou competências que precisarão ser desenvolvidos em determinado tempo. É uma maneira de fugir de métodos mais tradicionais e construir uma escola para o conhecimento e saberes práticos.

Não pretendem uma pedagogia centrada nos conteúdos. Por esta razão, defendem conteúdos formativos socialmente úteis, pois acreditam que os conteúdos são instrumentos para atingir os objetivos ligados ao ensino e a capacitação e, por isso, precisam ser conteúdos selecionados adequadamente para atingir os objetivos formativos. Desta maneira, são socialmente úteis os voltados para o interesse da classe trabalhadora, dos grupos dominados, contribuindo para a concretização dos demais princípios. O trabalho para proposta educacional do MST é central, já que vincula educação e trabalho como uma condição necessária para atingir os objetivos políticos e pedagógicos, ou seja, educação para o trabalho e pelo trabalho. Nessa perspectiva, os sujeitos da ação que se pretendem criar pela educação são principalmente trabalhadores militantes.

O vínculo orgânico entre processos educativos e processos políticos entendem processos políticos como parte de tudo que fazemos, assim, educação é uma prática política, e o vínculo orgânico entre educação e política, propõe para educação e seus processos pedagógicos, um entrelaçamento com a política, não apenas a abordagem de questões políticas, mas cultivar a criticidade dos educandos frente às injustiças, problematizando a realidade, dando oportunidade aos educandos a participar das ações de organização e luta do Movimento. Vínculo orgânico entre processos educativos $e$ econômicos - dá continuidade a ideia de unir educação às questões da vida e, os processos econômicos, fazem parte da 
produção e distribuição de bens e consumos necessários para todos. É possível, através de práticas pedagógicas, inserir algum tipo de processo econômico que aconteça fora ou dentro da escola, pois na proposta defendida pelo MST, acreditase que não se deva fugir das questões ligadas à economia como se pensou durante muito tempo, mas mostrar tipos de relações econômicas diferentes das existentes.

A relação entre educação e cultura deve estar ligada por um vínculo orgânico “... É a cultura que permite a comunicação humana e, portanto, permite a própria educação". (Caderno $\mathrm{n}^{\circ}$ 8, 1996). A educação tem um papel no processo de construção da identidade cultural dos trabalhadores do MST. No vínculo orgânico entre educação e cultura - as escolas e os cursos precisam ser espaços para a vivência e a produção de cultura, principalmente produzir uma nova cultura para mudança, que valoriza as experiências passadas, o presente e um projeto utópico futuro.

Para as escolas do MST a pesquisa é um instrumento importante no processo educativo. Nas atitudes e habilidades de pesquisa, “... pesquisa neste princípio é igual à investigação sobre uma realidade, quer dizer um esforço sistemático e rigoroso que se faz para entender mais a fundo (cientificamente), aquilo que é para nós um problema". (Caderno $\left.\mathrm{n}^{\circ} 8,1996\right)$. A prática da pesquisa nas escolas deve estar relacionada com o próprio princípio de relacionar teoria e prática e precisa ser constituído com uma metodologia de educação condizente com as diferentes idades, interesses e contexto de cada processo pedagógico. Lembram igualmente do princípio de capacitação onde o saber pesquisar está no âmbito do saber fazer e do saber ser.

Os educandos precisam não apenas debater o tema democracia, mas vivenciar na prática a participação democrática, educando-se, através da democracia social e para ela - gestão democrática - a direção coletiva do processo pedagógico. Deve ocorrer com a participação, além dos participantes diretos da escola também com a participação da comunidade de assentamentos e acampamentos para gestão da escola, e a gestão em relação com as demais escolas do MST. Apontam uma das dimensões da gestão democrática como sendo - auto-organização dos/das estudantes. Baseiam-se na expressão autoorganização criada no coletivo de alunas e alunos do pedagogo russo Pistrak. Tem na auto-organização como processo de criação do coletivo de alunos.

Igualmente é necessária a formação permanente dos professores, pois 
assinalam a importância da educação permanente de quem educa, e os coletivos pedagógicos têm este papel, através de todas as trocas, reflexões, estudos entre outros, feitas nestes momentos de formação coletiva, além do papel de alimentar o direito de sonhar e de criar coisas novas. Combinação entre processos pedagógicos coletivos e individuais - os princípios pedagógicos construídos centram-se na pessoa, mas não isolada, e sim como sujeito de relações com outras pessoas em um determinado contexto. “... a partir de nossas práticas já pudemos verificar a verdade do princípio que diz; ninguém aprende por ninguém, ninguém se educa por alguém, mas também ninguém se educa sozinho". (Caderno $\left.n^{\circ} 8,1996\right)$. $\mathrm{O}$ processo educativo acontece em cada pessoa, mas acontece também no sentido onilateral, o sujeito se relacionando com outros. Não é apenas a relação professorestudante que educa, mas todas as relações entre os estudantes e do educador com estes, num processo em que todos se educam.

De certo, os princípios filosóficos e pedagógicos do projeto educacional para os sujeitos de pertença do MST norteiam um processo educativo que aconteça para além dos espaços escolares formais, anunciando uma proposta de mudança e de esperança a favor de uma educação cidadã que forma, emancipa e que promove a transformação social. $\mathrm{O}$ movimento considera a educação essencial para a efetivação do seu projeto sociopolítico, junto na luta pelo acesso a terra, das condições de trabalho e permanência no meio rural com a conquista da Reforma Agrária. Para tanto, defende uma educação de qualidade voltada para a realidade do campo, ao mesmo tempo, luta pela democratização da gestão. Uma proposta para atender aos anseios do educando/trabalhador, dando a mesma importância para o trabalho intelectual e manual - de tal modo observado em seus princípios filosóficos e pedagógicos - uma proposta para romper com a dicotomia, ou no pensamento gramsciano - por fim entre a separação do Home faber e Homo sapiens.

\section{Práticas educativas mais abrangentes}

Hoje vivemos a era da comunicação digital, informações chegam o tempo todo sem conseguirmos filtrá-las, assim, para tanta informação, a criticidade é um componente indispensável na construção da identidade. É preocupante o excesso de propagandas que cria uma necessidade de consumo sem considerar a realidade de grande parte da população. Dessa forma, muitas vezes a desigualdade social/cultural fica escamoteada, busca-se a naturalização 
das condições degradantes do ser humano, visto que, a preocupação é apenas a venda do produto; portanto, retratam um modelo de sociedade ideal que não existe.

A linguagem de uma sociedade de consumo costuma promover que todas as pessoas estão em igualdade de condições para consumir, ignorando as limitações de um grande número delas para exercer essas ações. Por exemplo, não se leva em conta de que modo influi o fato do pertencimento ou não a um determinado grupo social, etnia ou certa faixa etária. Uma sociedade consumista, como a promovida pelo mercado, também não é uma sociedade em que surjam com facilidade com ideais de maior justiça social e de maior democratização das instituições sociais. $\mathrm{O}$ hiperindividualismo reinante nesses modelos competitivos propicia valorações diferentes das pessoas abastadas e comportamentos como "salve-se quem puder". As pessoas não entendem as responsabilidades que tem em relação ao bem estar dos demais. Essa mesma lógica de mercado leva as grandes empresas multinacionais se beneficiar com a exploração do trabalho infantil, do trabalho escravo de muitas mulheres do Terceiro Mundo, da impunidade para contaminar ou devastar o meio ambiente, etc. (Santomé, 2003, p. 90. Grifos do autor).

Os mercados em sua lógica ao pensar apenas na lucratividade, enaltecem comportamentos individualistas e de competitividade sem valorizar a realidade de crianças que pertencem a grupos sociais e etnias diferentes. Os meios de comunicação são também veículos de propagandas que inculcam um desejo ao consumo, e as crianças mais vulneráveis são alvo da lógica do mercado a qual não leva em conta as suas realidades. Uma lógica que permite abusos, até degradações humanas como a exploração do trabalho.

Frente a essa realidade, o MST como prática educativa mais abrangente, promove alternativas para desenvolver $\mathrm{o}$ senso crítico desde a infância, pois cria meios de comunicação específicos para o público infantil dos vários assentamentos e acampamentos e em suas escolas espalhadas pelo Brasil, possibilitando aos Sem Terrinha saber mais sobre história do MST, igualmente para participarem das publicações e trocarem informações uns como os outros. "As nossas crianças necessitam de valores que forme o seu caráter de um jeito diferente daquele que a televisão forma, daquele que as famílias capitalistas formam. As crianças precisam aprender a lutar e a ser firmes na luta." (MST, 1993).

O Setor de Comunicação conta com publicações de livros, vídeos, jornal, revista e a página dos Sem Terrinha onde são divulgadas as contribuições das crianças, como cartas, poemas, desenhos, entrevistas entre outros, e temas que envolvem trabalho, educação, história, mística do Movimento, e também atividades lúdicas. Estes instrumentos de comunicação divulgam as ações do 
Movimento e ao mesmo tempo documentam o processo de luta. Assim, podem informar sobre as mobilizações dos Sem Terrinha em Eventos, Encontros, Marchas e outras manifestações.

\section{O Jornal}

Um exemplo de veículo de comunicação que se mantém periodicamente no Movimento é o Jornal Sem Terra. Este instrumento é parte efetiva do projeto de comunicação e formação do MST, e existe a mais de trinta anos, discutindo temas proeminentes para os movimentos sociais e refletindo sobre a realidade social, econômica e política do país.

O Jornal Sem Terra é parte da trajetória de mobilizações e lutas pela Reforma Agrária e atua também como porta-voz do Movimento. Em 1986, ganhou o Prêmio Vladimir Herzog de Direitos Humanos, do Sindicato dos Jornalistas Profissionais do Estado de São Paulo. Há 31 anos, é publicado ininterruptamente. Em sua característica e vinculação à luta pela Reforma Agrária, pode-se afirmar que é o periódico de maior longevidade na história dos movimentos camponeses no Brasil. (Barros, 2013, p. 105-106).

O Jornal Sem Terra passou a vincular o encarte do Jornal Sem Terrinha a partir 2007 criando um espaço para noticiar a vivência dos Sem Terrinha de todo o país, o qual é um veículo para informar, ensinar, entreter e aprender com diversão.

Na edição de julho de 2008 o Jornal Sem Terrinha redigiu o tema especial do Saci-Pererê e, no texto "Em busca das Nossas Raízes", cita o escritor e sociólogo Monteiro Lobato como sonhador de um mundo com justiça social e alegria. Criou personagens infantis muito inteligentes e a até uma boneca de pano cheia de ideias convivendo no sítio do Pica-Pau Amarelo, cheio de fantasias e seres mágicos. Assim, no sítio crianças e adultos aprendem juntos, pois respeitam as ideias uns dos outros. Monteiro Lobato também estava preocupado com a valorização dos costumes e raízes do país, atentando-se para a formação da identidade brasileira, pois criticava quem insistia em copiar tudo que vinha de fora do país. Monteiro Lobato em seu contexto foi um exemplo de luta por suas raízes e valorização das ideias das crianças.

A respeito da Jornada dos Sem Terrinha na edição de setembro de 2010 é divulgada a chamada para um debate sobre as relações de poder para contribuir na formação político-organizativa das crianças nas reuniões, decidindo com elas sobre o Encontro Regional, Encontro Estadual e o que pode ser feito para ajudar e ter um encontro das escolas dos acampamentos, assentamentos e da região. 
É sugerido discutir com as crianças os problemas e dificuldades envolvendo-as nas tarefas que possam contribuir diretamente no Encontro. O Jornal Sem Terrinha contribui significativamente na divulgação das mobilizações, dando sugestões para organização das crianças, anterior aos Encontros e depois na divulgação dos resultados.

Na publicação de outubro de 2010 o tema apresentado sobre os meios de comunicação chamou a atenção, pois inicia falando sobre a importância da conquista dos próprios meios de comunicação como o Jornal Sem Terrinha, o Jornal Sem Terra e as rádios nos assentamentos e acampamentos. A matéria explana sobre as linguagens e os meios de comunicação existentes em nossa sociedade. Questiona como são feitos e por quem, esclarecendo que hoje os grandes meios de comunicação são propriedades de poucas pessoas muito ricas, além de questionar se os donos das grandes redes de comunicação permitiriam a todos falarem o que pensam e sentem. Além disso, coloca a importância de aprenderem a respeito dos meios de comunicação e notarem que nem tudo que se vincula é verdade. A matéria, enfim, questiona se as crianças e adolescentes já pararam para pensar como a mídia retrata o Movimento, e este questionamento estimula um exercício de reflexão muito importante, porque provavelmente as crianças e adolescentes já viram em alguma mídia comentários negativos sobre as ocupações e mobilizações dos Sem Terra e Sem Terrinha.

O Jornal Sem Terrinha construído pelo Movimento divulga os acontecimentos atuais e do passado, retrata a memória e o processo de luta, ensina sobre o Movimento e o mundo, fala do sonho de uma realidade nova, por isso, luta por um mundo mais solidário e sustentável. O jornal insere crianças e adolescentes no contexto informativo e cultural que valoriza a identidade Sem Terra. Há um diferencial em relação às publicações de massa com apelo comercial, pois não foi visto nenhum, pelo contrário, apresenta às crianças uma visão crítica do que é veiculado nas mídias em geral, além de ensinar práticas saudáveis como a produção de alimentos orgânicos, consumo sustentável, contato com a natureza, entre outros.

\section{A Revista}

O Movimento no ano de 2009 lançou a Revista Sem Terrinha, um canal de comunicação mensal do MST de todo o Brasil, visto que é um espaço para aprender sobre a vida dos Sem Terrinha e para divulgar atividades, produções e assuntos de interesse. A revista é elaborada 
coletivamente pelos Setores de Educação, Comunicação e Cultura. Os desenhos são feitos por crianças Sem Terrinha de todo o Brasil, e na composição da Revista buscam revelar as histórias e a participação das crianças no Movimento.

Na edição número 5 a Revista traz a história das crianças que fizeram uma investigação sobre o Congresso muito interessante. Os Sem Terrinha em forma de brincadeira organizaram-se em reuniões para participar do Congresso, depois resolveram contar para os adultos o que tinham discutido e feito para o Congresso. Em uma reunião da coordenação pediram para se pronunciar, colocaram uma música e distribuíram um símbolo para cada um da coordenação. Cada símbolo era parte de um quebra cabeça e todos tinham que colocar sua peça para formar a figura da bandeira do MST. Os adultos ficaram encantados com a iniciativa. A bandeira constitui-se um símbolo do MST adotado em 1987 como uma representação mística importantíssima. Junto com o hino e outras simbologias a bandeira é parte do processo de construção de Identidade do Movimento.

Ainda na mesma revista na página 14 no texto "O significado dos símbolos" há uma menção aos componentes da bandeira: o vermelho é o vigor, a força, a energia e o sangue derramado pelos que morreram na luta. O verde do mapa é a defesa da vida da natureza. O casal é a família unida na luta pela terra. As letras pretas representam a noite como abrigo para entrar nas fazendas, sem chamar a atenção dos inimigos, e o branco convidando para a convivência e o facão como instrumento de trabalho e luta.

A bandeira está presente nas ocupações e mobilizações do MST, representa um símbolo de força para os Sem Terra, por isso, ficaram emocionados com a criatividade e escolha dos Sem Terrinha. Além do mais, as crianças fizeram cartazes para dizer que tinham ouvido falar do Congresso e queriam participar, ainda tinham feito reuniões escondidos, mas mudaram os planos, achavam que não precisam mais ir ao Congresso, afinal quem fosse, levaria o que discutiram de coisas boas e ruins, o que desejariam mudar e o que desejariam preservar no Movimento. Os Sem Terrinha perguntaram para as pessoas mais velhas sobre como foram os outros Congressos e descobriram que o mais importante eram as reuniões, assim o Congresso só ia dar certo se o debate fosse feito nos assentamentos e acampamentos, porque só desta forma quem fosse ia representar as decisões do coletivo. Apesar do objetivo de o grupo das crianças ter mudado, a coordenação do assentamento discutiu a importância de levar o grupo e, 
assim, se somaram outros grupos para participarem do VI Congresso Nacional do MST.

Nas revistas aparecem as histórias incluindo vivências dos Sem Terrinha nos assentamentos e acampamentos, ensinamentos sobre a organização dos Setores e das Instâncias de luta, a mística, sobre as escolas e a vida dos Sem Terrinha e suas famílias de uma maneira contextualizada e divertida para o público infantil. A revista é rica em conhecimento, imagens das crianças e desenhos, conseguindo transmitir perfeitamente o que o Movimento construiu nos últimos anos e o que ele representa.

A ênfase da luta dos Sem Terrinha é a luta pela escola, por melhorias na educação do campo, por uma educação voltada para realidade camponesa, pensada para desenvolver a criticidade e autonomia com base em princípios do Movimento. Os meios de comunicação criados para 0 público infantil do MST permitem a participação das crianças e adolescentes por meio das suas produções e corroboram na formação da identidade.

Também no site do MST foi criada a seção dos Sem Terrinha. A página é um espaço onde as crianças podem encontrar os debates do Movimento em uma linguagem acessível e conhecer sobre a realidade onde estão como sujeitos, mesmo que ainda muito jovens, mas que estão inseridos e vivendo intensamente $o$ processo histórico de luta do Movimento. Encontramos na página dos Sem Terrinha: cores alegres, desenhos infantis, cartas, histórias, jogos, músicas, também a possibilidade de acesso aos jornais e revistas. Na página há sugestões de leituras para os Sem Terrinha e Educadores e sugestões de outros sítios como: Portal Cultura e Infância, Palavras Cantadas, Grupo Encantar, Menino Maluquinho, entre outros.

A página no site é mais uma prática para integrar a criança ao Movimento e embora a conquista da página represente um ganho importante para o Movimento, ainda lutam para que todos os assentamentos tenham acesso à Internet. Este acesso insere-se na luta para conquista de escolas com estrutura adequada com Internet e demais recursos.

Devemos trabalhar num plano concreto para que se democratize a toda a população do continente o acesso a internet e a meios de comunicação (como televisão, rádio etc.) sob seu controle. Para que a população tenha acesso a informação verdadeira e para que as forças sociais e populares controlem os meios de comunicação de massa, evitando que sejam apenas instrumentos de lucro e de manipulação ideológica pelas classes dominantes. (MST, 2007, p. 104). 
A exclusão social apresenta muitas configurações no mundo todo - na modernidade uma nova exclusão precisa ser vencida - a exclusão digital, por isso, o MST entende a importância das forças sociais e populares controlar os meios de comunicação de massa para a garantia de acesso a informações relevantes e verdadeiras.

\section{Mobilização}

O MST afirma que procura estimular a criatividade de suas educandas e educandos para expressarem-se a partir da realidade de luta do povo. Criam meios para os Sem Terrinha mostrarem como pensam e se sentem nas mobilizações culturais que existem desde o primeiro Concurso Nacional de Literatura e Artes Plásticas, realizado em 1998 pelo Setor de Educação. Todas as edições dos Concursos tiveram temáticas sobre o momento debatido e vivenciado no MST e no país. O $1^{\mathrm{o}}$ Concurso Nacional aconteceu em 1998, realizou-se com o tema "O Brasil que queremos". Os participantes puderam expressar, por meio da redação e do desenho, suas compreensões frente à realidade do país.

Desta maneira, as mobilizações dos Sem Terrinha estão presentes nos Encontros, Concursos Nacionais, acampamentos-escola, participação em feiras de ciências, olimpíadas, festivais e trazem a identidade das crianças Sem Terrinha; entretanto, esse processo encontra desafios para sua realização, como, por exemplo, o encontro dos Sem Terrinha caracterizado pela mobilização que vem acontecendo com muitos militantes, além de trabalho intenso de preparação de material durante todo o ano letivo e, principalmente, nos dias que acontecem o Encontro. "Cada tipo de mobilização exige um processo diferente de preparação e nenhuma delas pode ser realizada sem uma preparação anterior intensiva, pois as crianças não podem participar sem saber o que está acontecendo, porque isso não é educativo." (MST, 1999, p. 40).

O trabalho educativo e pedagógico realizado com os Sem Terrinha após as mobilizações é uma tarefa que o MST acredita ser imprescindível para dar continuidade ao processo até a próxima mobilização. A organização dos Sem Terrinha nas mobilizações, como já mencionado, pode envolver a escola, mas tem sido feita, na maioria das vezes, nos assentamentos e acampamentos ou, ainda, nos grupos que reúnem as famílias. "Cada atividade exige um trabalho posterior seja significativo, educativo, é preciso que haja muita seriedade na observação e acompanhamento de cada criança que 
participa da mobilização. Geralmente há aquelas que se estacam, que se descobrem, que se metem e participam ativamente." (MST, 1999, p. 40).

Para os encontros das crianças e adolescentes Sem Terrinha são definidos objetivos gerais para as atividades desenvolvidas, visto que as crianças escolhem representantes para participarem das reuniões de preparação dos eventos. "Preparar atividades culturais a serem apresentadas no encontro; providenciar seus pertences pessoais para levar ao encontro; escolherem seus representantes para participarem das reuniões de preparação, juntamente com os professores e pais; preparar a mística, ensaiar os cantos e ensaios.” (MST, 1999, p. 45).

Desde 1994, geralmente no mês de outubro, e corresponde à Semana da Criança. Esta atividade faz parte do processo de organização das crianças dos acampamentos e assentamentos do MST e é realizada nos estados em que o MST está organizado tendo uma abrangência regional ou estadual, dependendo das condições de cada Estado. A duração, em média, é de 3 a 4 dias. $\mathrm{O}$ número das crianças participantes no encontro também varia conforme o estado: há casos contabilizados de $150 \mathrm{ou}$, até mesmo, 700 crianças. O Estado do Pernambuco tem a experiência de ter realizado encontros com a participação de duas mil crianças. Em alguns Estados, os encontros têm caráter mais reivindicatório; em outros, de estudo, lazer e troca de experiências; em alguns, juntam-se o caráter da reivindicação ao estudo e lazer. Geralmente, o centro da reivindicação é a luta por escolas adequadas nos assentamentos $\mathrm{e}$ acampamentos. No Estado de São Paulo, ocorreram três encontros: o $1^{\mathrm{a}}$ Encontro Estadual Infanto Juvenil, nos dias 12, 13 e 14 de outubro de 1996, com 700 crianças. Foi neste encontro, na fase preparatória, que as crianças sem terra começaram a se identificar como Sem Terrinha, ou seja, começaram a assumir a identidade própria das crianças Sem Terra. (Rosseto, 2009, p. 33-34).

No mês de outubro no dia das crianças os Sem Terrinha despontam com suas manifestações atribuindo um significado maior a esta data quando participam da Jornada do MST. A escola de acampamento e assentamento pode envolver-se no processo de organização das mobilizações dos Sem Terrinha. Fazer um trabalho anterior abordando as temáticas para a mobilização e contribuir durante o momento da mobilização e posteriormente com um trabalho dando continuidade as aprendizagens de organização política vivida por meio das ações nas mobilizações. Para tanto, faz-se necessário um esforço da equipe e envolvimento do Movimento com a escola para que aconteça a participação dos alunos em eventos a partir da organização feita na escola.

\section{Considerações finais}

Este estudo salientou uma educação com sentido para os sujeitos, derivando em aprendizagem para a vida, porquanto 
apontou uma educação não restrita aos muros da escola. Todavia, colocou que o ensino sistematizado deva alcançar do mesmo modo os que mais precisam, por isso, a reflexão em diferenciar a prática pedagógica, em equacionar uma nova concepção-uma nova didática, quando a nossa cabeça estiver se libertando de preconceitos, individualismo e receios inculcados desde a nossa formação, ao mesmo tempo, ousarmos novas práticas, na educação infantil até a faculdade, em um trabalho conjunto.

O estudo referiu às ações do MST como práticas educativas mais abrangentes que interliga a vida do campo e educação, e põe a escola na realidade de luta pela terra, pelo trabalho, enfim, pela dignidade humana. Os princípios pedagógicos foram elucidados para retratar a concepção de educação do MST, para escolas e cursos de formação, a exemplo os princípios vínculo orgânico entre processos educativos e processos políticos, autoorganização, entre outros, foram notados nas práticas educativas mais abrangentes ao criarem para crianças e adolescentes meios de se mobilizarem. Os próprios veículos de comunicação (revista, jornal, site, etc.) com potencial de educar criticamente o olhar, pois contam a história do povo lutador, valorizam suas raízes, visto que essas práticas tem um caráter de formação política e humana para a vida.

Finalmente, a própria vivência culminando com a realização deste estudo gerou a reflexão de que na ação, ao ousar novas práticas nossa cabeça começa a mudar, então passamos a diferenciar as práticas para mediar um ensino com sentido aos que mais precisam. Assim, somente a prática diferente permite mudarmos a forma de pensar. Não é tarefa fácil, pois é uma luta constante com a cabeça velha, mas a ação nova tem potencial para extinguir a velha.

É preciso reconhecer de uma vez por
todas que a criança e, sobretudo, o
adolescente, não se preparam apenas
para viver, mas já vivem uma
verdadeira vida. Devem
consequentemente organizar esta
vida. A auto-organização deve ser
para eles um trabalho sério,
compreendendo obrigações e sérias
responsabilidades. Se quisermos que
as crianças conservem o interesse
pela escola, considerando-a como seu
centro vital, como sua organização, é
preciso nunca perder de vista que as
crianças não se preparam para se
tornar membros da sociedade, mas já
o são, tendo já seus problemas,
interesses, objetivos, ideais, já
estando ligadas à vida dos adultos e
do conjunto da sociedade. (Pistrak,
2000, p. 42.43).

A partir da constatação de que as crianças e adolescentes são capazes de se organizarem e terem suas opiniões, fica claro que buscam sentido no que realizam, já que não são inseridas futuramente na 
sociedade, mas fazem parte dela no presente. Muitas vezes não possuem a criticidade para analisar as mazelas sociais, mas sofrem suas consequências. Para tanto, é necessário refletirmos em 'práticas educativas' na escola e na vida, centradas no autoritarismo e na indiferença ao sujeito, desafio que com certeza necessita de mobilização. Nesse sentido, o MST contribui, pois visa ações para a conquista da terra, do direito ao trabalho e qualidade de vida no campo, essa dignificação da vida rural é defendida na luta por uma educação mais abrangente, por isso, princípios e práticas diferenciadas que gerem transformações, valorizando tanto o trabalho na terra (braçal) como os estudos (intelectual).

\section{Referências}

Barros, M. R. de S. (2013). Os Sem terrinha: uma história da luta social no Brasil (1981-2012). (Dissertação de Mestrado). Universidade Federal do Ceará, Fortaleza.

Freire, P. (1982). Pedagogia do Oprimido. Rio de Janeiro, RJ: Paz e Terra.

Mészáros, I. (2008). A educação para além do capital. São Paulo, SP: Boitempo.

MST. (1996). Princípios da educação no MST. Caderno de Educação, (8).

MST. (1999). Crianças em Movimento: As Mobilizações Infantis no MST. Coleção Fazendo Escola (2). São Paulo.
MST. (2007). Cartilha "Textos para estudo e debate". $5^{\circ}$ Congresso Nacional do MST Reforma Agrária: Por Justiça Social e Soberania Popular.

MST. (2011). Educação da Infância Sem Terra. Orientação para o trabalho de base. In Caderno a infância. (1). São Paulo.

Neto, B. A. (2009). A educação rural no contexto das lutas do MST. Campinas, SP: Autores Associados.

Pistrak, M. (2000). Fundamentos da escola do trabalho. São Paulo, SP: Expressão Popular.

Rosseto, E. R. A. (2009). Essa ciranda não é minha só, ela é de todos nós: a educação de crianças sem terrinha no MST. (Dissertação de Mestrado). Universidade Estadual de Campinas, São Paulo.

Santomé, J. T. (2003). A educação em tempos de neoliberalismo. Porto Alegre, RS: Artmed.

Recebido em: 10/07/2016 Aprovado em: 08/09/2016 Publicado em: 19/04/2017

Como citar este artigo / How to cite this article / Como citar este artículo:

APA:

Mata, L. K. L. (2017). Notas sobre práticas educativas diferenciadas no MST: os princípios pedagógicos revelados a partir de algumas metodologias empregadas na educação do movimento. Rev. Bras. Educ. Camp., 2(1), 68-85.

ABNT:

MATA, L. K. L. Notas sobre práticas educativas diferenciadas no MST: os princípios pedagógicos revelados a partir de algumas metodologias empregadas na educação do movimento. Rev. Bras. Educ. Camp., Tocantinópolis, v. 2, n. 1, p. 68-85, 2017. 